\title{
Strontium and barium iodide high light yield scintillators
}

\author{
Nerine J. Cherepy, ${ }^{1, a)}$ Giulia Hull, ${ }^{1}$ Alexander D. Drobshoff, ${ }^{1}$ Stephen A. Payne, ${ }^{1}$ \\ Edgar van Loef, ${ }^{2}$ Cody M. Wilson, ${ }^{2}$ Kanai S. Shah, ${ }^{2}$ Utpal N. Roy, ${ }^{3}$ Arnold Burger, ${ }^{3}$ \\ Lynn A. Boatner, ${ }^{4}$ Woon-Seng Choong, ${ }^{5}$ and William W. Moses ${ }^{5}$ \\ ${ }^{1}$ Lawrence Livermore National Laboratory, Livermore, California 94550, USA \\ ${ }^{2}$ Radiation Monitoring Devices, Boston, Massachusetts 02134, USA \\ ${ }^{3}$ Center for Physics and Chemistry of Materials, Fisk University, Nashville, Tennessee 37208, USA \\ ${ }^{4}$ Oak Ridge National Laboratory, Oak Ridge, Tennessee 37831, USA \\ ${ }^{5}$ Lawrence Berkeley National Laboratory, Berkeley, California 94720, USA
}

\begin{abstract}
Europium-doped strontium and barium iodide are found to be readily growable by the Bridgman method and to produce high scintillation light yields. $\mathrm{SrI}_{2}(\mathrm{Eu})$ emits into the $\mathrm{Eu}^{2+}$ band, centered at $435 \mathrm{~nm}$, with a decay time of $1.2 \mu$ s and a light yield of $\sim 90000$ photons/MeV. It offers energy resolution better than $4 \%$ full width at half maximum at $662 \mathrm{keV}$, and exhibits excellent light yield proportionality. $\mathrm{BaI}_{2}(\mathrm{Eu})$ produces $>30000$ photons $/ \mathrm{MeV}$ into the $\mathrm{Eu}^{2+}$ band at $420 \mathrm{~nm}(<1 \mu \mathrm{s}$ decay). An additional broad impurity-mediated recombination band is present at $550 \mathrm{~nm}(>3 \mu \mathrm{s}$ decay), unless high-purity feedstock is used.
\end{abstract}

Detection sensitivity for weak gamma ray sources and rapid unambiguous isotope identification are principally dependent on energy resolution, and are also enhanced by high effective atomic number of the detector material. The inorganic scintillator currently providing the highest energy resolution is $\mathrm{LaBr}_{3}(\mathrm{Ce}), \sim 2.6 \%$ at $662 \mathrm{keV},{ }^{1-3}$ but it is highly hygroscopic, possesses intrinsic radioactivity due to the presence of primordial ${ }^{138} \mathrm{La}$, and its crystal growth is still challenging. Strontium and barium iodide doped with europium are readily growable orthorhombic crystals that offer low phonon frequencies, moderate density, $\rho=4.6$ and $5.1 \mathrm{~g} / \mathrm{cm}^{3}$, respectively, equivalent or higher light yields than $\mathrm{LaBr}_{3}(\mathrm{Ce})$ and no intrinsic radioactivity.

Reports of alkaline earth halide scintillation originate with Hofstadter et al. on calcium iodide in the 1960s. ${ }^{4} \mathrm{Cal}-$ cium iodide exhibits light yields of $\sim 100000$ photons $/ \mathrm{MeV}$ and has been activated with $\mathrm{Tl}^{+}$and $\mathrm{Eu}^{2+}$; however, it is nearly impossible to grow substantial $\mathrm{CaI}_{2}$ crystals due to its platelet growth habit. While Hofstadter et al. patented the $\mathrm{SrI}_{2}(\mathrm{Eu})$ crystal in $1968,{ }^{5}$ no isotope-identifying devices based on this material were ever reported. A report on cathodoluminescence from $\mathrm{Ca}, \mathrm{Sr}$, and $\mathrm{Li}$ halides described efficient $\mathrm{Eu}^{2+}$ activation and moderate hygroscopicity. ${ }^{6} \mathrm{~A}$ few studies of scintillation from undoped $\mathrm{BaI}_{2}$ have appeared. ${ }^{7.8}$ The efforts of Selling et al. to observe scintillation from $\mathrm{Eu}^{2+}$ doped $\mathrm{BaI}_{2}$ reported a light yield of 2000 photons $/ \mathrm{MeV}^{9}{ }^{9}$ In recent years, this class of materials has been largely ignored for scintillation applications.

Strontium iodide was grown at Radiation Monitoring Devices (RMD) while barium iodide crystals were grown at Fisk University, Oak Ridge National Laboratory and RMD; all in quartz crucibles using the Bridgman method. The melting points of $\mathrm{SrI}_{2}$ and $\mathrm{BaI}_{2}$ are 515 and $711^{\circ} \mathrm{C}$, respectively; both possess orthorhombic symmetry ${ }^{9.10}$ (while calcium iodide is hexagonal ${ }^{4}$ ). All crystals described in this letter were doped with 0.5 mole $\%$ europium and were several cubic centimeters per boule, then cut into $\sim 1 \mathrm{~cm}^{3}$ pieces for evalu-

\footnotetext{
Tel.: 925-424-3492. FAX: 925-423-8772. Electronic mail: cherepy $1 @ 11 n$ l.gov.
}

ation. Barium iodide as-supplied powder, $99.995 \%$ pure ultradry (Alfa Aesar) was yellowish in color (thought to be due to oxide or oxyiodide contamination). Crystals grown directly from as-supplied powders retained a dark coloration (referred to henceforth as "first crystal"). Zone refining rendered the starting powders colorless, and the resulting pure powders were used to grow several crystals (referred to as "second crystal," although several were grown following this procedure). Finally, an ultrapurification method was used at $\mathrm{RMD}$ to grow a $\mathrm{BaI}_{2}(\mathrm{Eu})$ crystal, referred to as "third crystal."

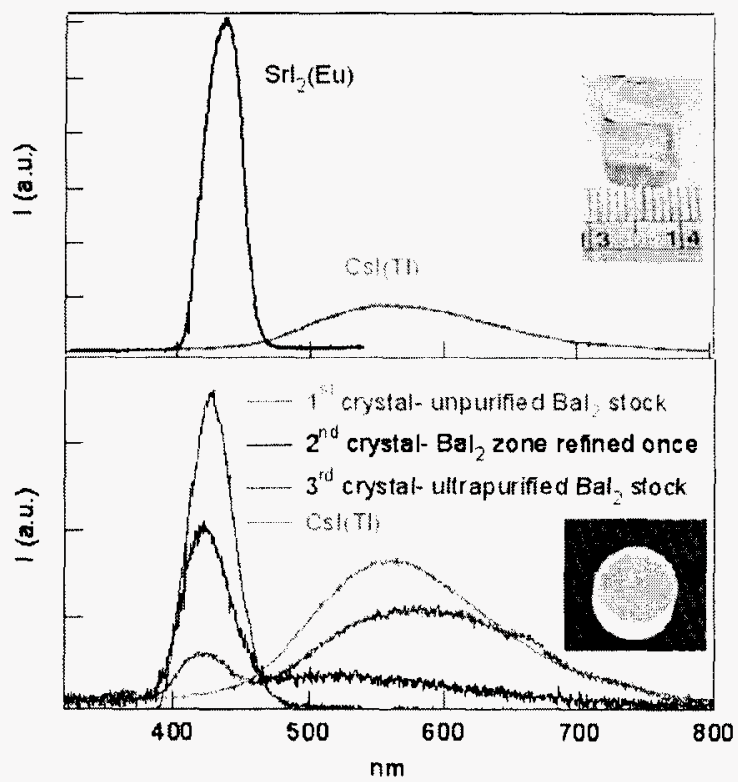

FIG. 1. (Color online) (Top frame) Beta-excited radioluminescence spectra acquired of $\mathrm{Srl}_{2}(\mathrm{Eu})$; (inset) $\mathrm{Srl}_{2}$ (Eu) crystal grown at RMD under $254 \mathrm{~nm}$ excitation. (Lower frame) Beta-excited radioluminescence from three $\mathrm{BaI}_{2}(\mathrm{Eu})$ crystals; (inset) $\mathrm{BaI}_{2}(\mathrm{Eu})$ crystal from Fisk University under $254 \mathrm{~nm}$ excitation. For $\mathrm{BaI}_{2}(\mathrm{Eu})$, the first crystal was grown from asreceived powders (red), the second crystal was grown from powders that had been zone refined once (black), and the third crystal was grown under ultrapure conditions. Light yields are plotted along with that of CsI(Tl) (green), and may be compared in an absolute sense. 


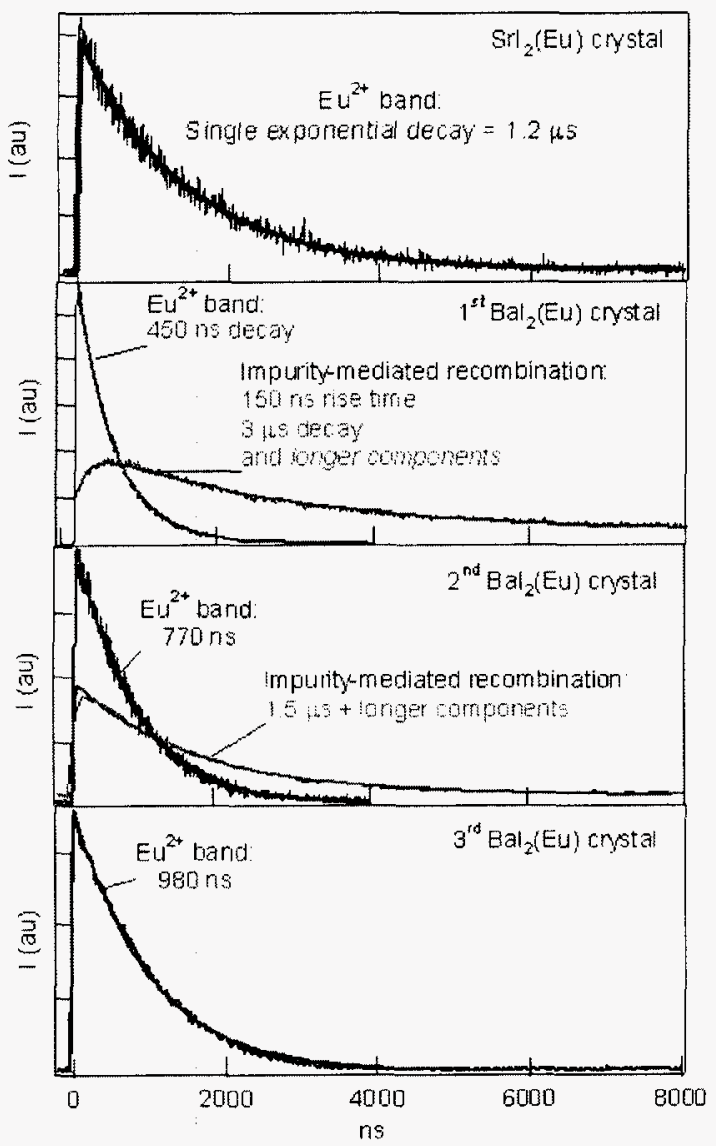

FIG. 2. (Color online) Time-resolved luminescence decays acquired by excitation with $30 \mathrm{~ns}$ laser pulses at $266 \mathrm{~nm}$. $\mathrm{BaI}_{2}(\mathrm{Eu})$ emission recorded at $420 \mathrm{~nm}$ for $\mathrm{Eu}^{2+}$ emission and at $600 \mathrm{~nm}$ for "impurity recombination" band.

Radioluminescence spectra were acquired using a ${ }^{90} \mathrm{Sr} /{ }^{90} \mathrm{Y}$ source (average beta energy $\sim 1 \mathrm{MeV}$ ) to provide a spectrum expected to be essentially equivalent to that produced by gamma excitation. Radioluminescence spectra were collected with a spectrograph coupled to a thermoelectrically cooled camera and corrected for spectral sensitivity. The beta-excited luminescence of $\operatorname{SrI}_{2}(0.5 \% \mathrm{Eu})$ compared to that of a standard scintillator crystal, $\mathrm{CsI}(\mathrm{Tl})$, is shown in Fig. 1 (top frame), along with a $\mathrm{SrI}_{2}(\mathrm{Eu})$ crystal grown at RMD (inset). It possesses a single band centered at $435 \mathrm{~nm}$, assigned to the $\mathrm{Eu}^{2+} d \rightarrow f$ transition, and an integrated light yield of 93000 photons/MeV. Figure 1 (bottom frame) shows beta-excited luminescence spectra of three $\mathrm{BaI}_{2}(\mathrm{Eu})$ crystals compared to a $\mathrm{CsI}(\mathrm{Tl})$ standard crystal. The $\mathrm{Eu}^{2+}$ luminescence at $\sim 420 \mathrm{~nm}$ is enhanced in the second $\mathrm{BaI}_{2}(\mathrm{Eu})$ crystal, while the $\sim 550 \mathrm{~nm}$ band is reduced, and for the third crystal, the $\sim 550 \mathrm{~nm}$ band is entirely absent. It is notable that the overall light yield is highest for the first crystal; its integral light yield (including both the $420 \mathrm{~nm}$ and the $550 \mathrm{~nm}$ bands) is 60000 photons $/ \mathrm{MeV}$. The weak band at $550 \mathrm{~nm}$ may be assigned to an impurity-mediated recombination transition.

Decay lifetimes were acquired using a flashlamppumped Nd:yttrium aluminum garnet laser at $266 \mathrm{~nm}$ with 20 ns pulses. Luminescence is collected with a monochromator coupled to an R928 Hamamatsu PMT and readout by an oscilloscope. In $\mathrm{SrI}_{2}(\mathrm{Eu})$, the $\mathrm{Eu}^{2+}$ band exhibits a $1.2 \mu \mathrm{s}$ decay (Fig. 2, top). Figure 2, second from top, shows that for

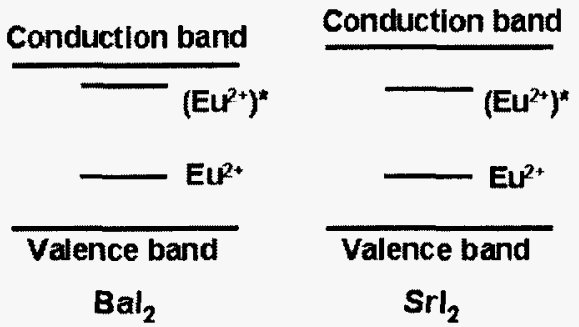

FIG. 3. (Color online) Postulated energy level diagram for the $\mathrm{BaI}_{2}(\mathrm{Eu})$ and $\mathrm{SrI}_{2}(\mathrm{Eu})$ systems.

the first $\mathrm{BaI}_{2}(\mathrm{Eu})$ crystal, the $\mathrm{Eu}^{2+}$ decay is $\sim 450$ ns while the impurity-mediated luminescence is slower, containing components that are longer than $8 \mu \mathrm{s}$. It is interesting that a component of the impurity-mediated recombination is prompt; an additional component forms by depopulating the $\mathrm{Eu}^{2+}$ excited state (possibly electrons trapped initially at $\mathrm{Eu}^{2+}$ thermally detrap to the conduction band), as revealed by a rise-time component. For the second $\mathrm{BaI}_{2}(\mathrm{Eu})$, the $\mathrm{Eu}^{2+} \mathrm{de}-$ cay is $\sim 770 \mathrm{~ns}$, as shown in Fig. 3 (third from top), effectively lengthened due to the reduction of detrapping and excitation transfer to the impurity-mediated recombination route. The third $\mathrm{BaI}_{2}(\mathrm{Eu})$ crystal exhibits an even slightly longer decay, $\sim 980 \mathrm{ns,}$, as impurity-mediated recombination has been eliminated. A diagram indicating a proposed energy level diagram for $\mathrm{SrI}_{2}(\mathrm{Eu})$ and $\mathrm{BaI}_{2}(\mathrm{Eu})$ is shown in Fig. 3.

Gamma ray spectra were acquired using a Hamamatsu R980 bialkali photomultiplier tube (PMT) (spectral sensitivity in 380-420 $\mathrm{nm}$ range is nearly constant $\sim 30 \%$ ). Crystals were centered on the entrance window, optically coupled to the PMT with mineral oil and wrapped with several layers of Teflon tape. The PMT signals were shaped with a Tennelec TC 244 spectroscopy amplifier [4 $\mu$ s shaping time for $\mathrm{SrI}_{2}(\mathrm{Eu})$ and $8 \mu$ s for $\left.\mathrm{BaI}_{2}(\mathrm{Eu})\right]$, then recorded with an Amptek MCA8000-A multichannel analyzer. The total gamma absorption peaks ("photopeaks") were fit to a Gaussian to evaluate the peak position and FWHM to estimate the scintillation light yield and the energy resolution, respectively. Gamma light yields are determined by direct comparison of the photopeak position for $\mathrm{SrI}_{2}(\mathrm{Eu})$ (channel No. 376;
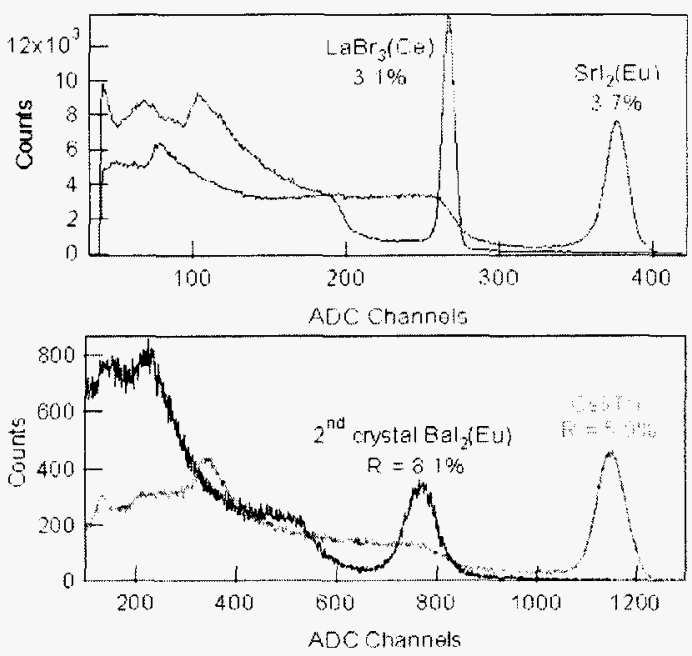

FIG. 4. (Color online) Pulse-height spectra acquired of a $\mathrm{SrI}_{2}(\mathrm{Eu})$ crystal grown at RMD (upper frame), yielding an energy resolution of $3.7 \%$ at $662 \mathrm{keV}$, and of the second crystal of $\mathrm{BaI}_{2}(\mathrm{Eu})$ (lower frame), yielding an energy resolution at $662 \mathrm{keV}$ of $8.1 \%$ 
TABLE I. Beta-excited light yields are acquired with a silicon CCD camera that integrates the luminescence spectrum over $30 \mathrm{~s}$; spectral sensitivity corrected for CCD and grating. Gamma-excited light yields are determined via pulse-height spectra, corrected for spectral sensitivity, and acquired at $662 \mathrm{keV}$ using a Hamamatsu R980 PMT (4-8 $\mu$ s shaping time).

\begin{tabular}{lccc}
\hline \hline & $\begin{array}{c}\text { Gamma } \\
\text { light yield } \\
\text { (photons/MeV) }\end{array}$ & $\begin{array}{c}\text { Beta } \\
\text { light yield } \\
\text { (photons/MeV) }\end{array}$ & $\begin{array}{c}\text { Energy } \\
\text { resolution } \\
(662 \mathrm{keV})\end{array}$ \\
\hline $\mathrm{CsI}(\mathrm{Tl})$ & $65000^{\mathrm{a}}$ & $65000^{\mathrm{b}}$ & $6.2 \%$ \\
$\mathrm{LaBr}_{3}(\mathrm{Ce})$ & $60000^{\mathrm{a}}$ & $60000^{\mathrm{b}}$ & $3.2 \%$ \\
$\mathrm{SrI}_{2}(\mathrm{Eu})$ & 85000 & 93000 & $3.7 \%$ \\
$\left(\right.$ First crystal) $\mathrm{BaI}_{2}(\mathrm{Eu})$ & 14000 & $60000^{\mathrm{c}}$ & $8.1 \%$ \\
(Second crystal) $\mathrm{BaI}_{2}(\mathrm{Eu})$ & 10000 & $35000^{\mathrm{c}}$ & $8.1 \%$ \\
(Third crystal) $\mathrm{BaI}_{2}(\mathrm{Eu})$ & 35000 & 40000 & $>10 \%$ \\
\hline \hline
\end{tabular}

${ }^{a}$ As quoted by crystal supplier.

${ }^{b}$ Assumed to be the same for betas and gammas.

${ }^{c}$ Includes both 420 and $550 \mathrm{~nm}$ luminescence bands.

85000 photons $/ \mathrm{MeV}$ ) and $\mathrm{LaBr}_{3}(\mathrm{Ce}$ ) (channel No. 266; 60000 photons $/ \mathrm{MeV}$ ). Figure 4 (top) shows the pulse-height spectra acquired using the $662 \mathrm{keV}$ gamma from ${ }^{137} \mathrm{Cs}$ for $\mathrm{SrI}_{2}(\mathrm{Eu})$ and $\mathrm{LaBr}_{3}(\mathrm{Ce})$ under the same conditions. Energy resolution at $662 \mathrm{keV}$ of $<4 \%$ and light yield significantly superior to that of $\mathrm{LaBr}_{3}(\mathrm{Ce})$ are reproducibly measured for $\mathrm{SrI}_{2}(\mathrm{Eu})$. Subsequent $\mathrm{SrI}_{2}(\mathrm{Eu})$ crystals grown by ORNL, with Eu doping of $4 \%$ and $6 \%$, exhibit gamma light yields in excess of 100000 photons $/ \mathrm{MeV}$, and similar energy resolution. In Fig. 4 (bottom), the pulse-height spectrum of the first $\mathrm{BaI}_{2}(\mathrm{Eu})$ crystal is reported, in comparison to $\mathrm{CsI}(\mathrm{Tl})$. Energy resolution at $662 \mathrm{keV}$ for the second $\mathrm{BaI}_{2}(\mathrm{Eu})$ crystal was measured to be $8 \%$. While the third $\mathrm{BaI}_{2}(\mathrm{Eu})$ crystal exhibited a gamma light yield of 35000 photons/ $\mathrm{MeV}$, its energy resolution was poor, possibly due to nonuniformity of doping and suboptimal optical quality. Table I summarizes light yield and resolution results. For $\mathrm{BaI}_{2}(\mathrm{Eu})$, the discrepancy between the beta and gamma integral light yields is due to delayed luminescence components. Figure 5 shows the energy resolution as a function of gamma ray energy for $\mathrm{SrI}_{2}(\mathrm{Eu})$ and $\mathrm{LaBr}_{3}(\mathrm{Ce})$ using Ba-133, Am-241, Co-57, Na22, Co-60, and Cs-137 sources along with a fit to Poisson statistics.

The scintillation light yield nonproportionality characterization instrument (SLYNCI), a unique facility for measuring the so-called nonproportionality of scintillator materials, is described in Ref. 11. Figure 6 shows the relative light yield as a function of electron energy for $\mathrm{Srl}_{2}(\mathrm{Eu})$, compared to that of $\mathrm{NaI}(\mathrm{Tl})$ and $\mathrm{LaBr}_{3}(\mathrm{Ce}){ }^{12,13}$ The light yield propor-

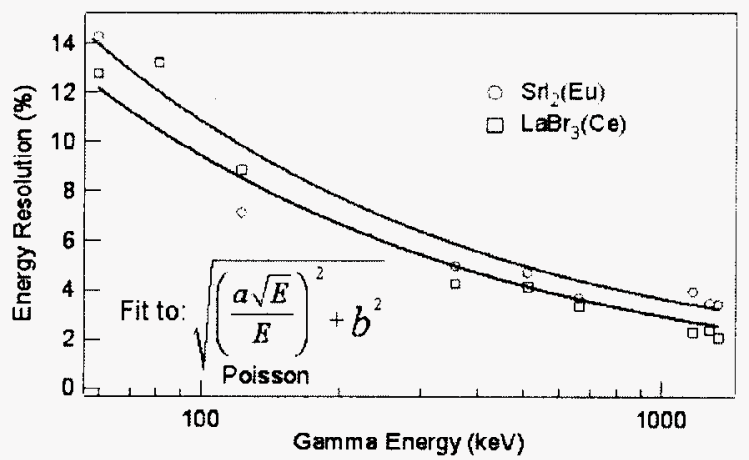

FIG. 5. (Color online) Pulse-height spectra provide the energy resolution as a function of gamma ray energy. Energy resolution is comparable between $\mathrm{LaBr}_{3}(\mathrm{Ce})$ and $\mathrm{SrI}_{2}(\mathrm{Eu})$ for all energies.

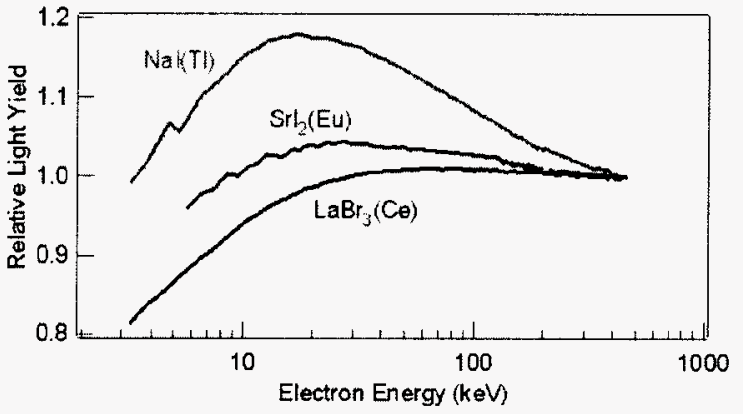

FIG. 6. (Color online) Relative light yields as a function of electron energy acquired using the SLYNCI reveal a proportional response for $\mathrm{Srl}_{2}(\mathrm{Eu})$, in comparison to both $\mathrm{LaBr}_{3}(\mathrm{Ce})$ and $\mathrm{NaI}(\mathrm{Tl})$.

tionality is excellent for $\operatorname{Srl}_{2}(\mathrm{Eu})$, and thus the contribution to energy resolution from nonproportionality may be small for $\operatorname{SrI}_{2}(\mathrm{Eu})$. This may be due to extremely efficient capture of excitation on $\mathrm{Eu}^{2+}$ sites, more independent of excitation density than for other scintillators. ${ }^{12,13}$ Future experiments will be needed to verify this expectation.

In summary, strontium iodide is a readily "growable" crystal that activates efficiently with $\mathrm{Eu}^{2+}$, yielding $>80000$ photons $/ \mathrm{MeV}$ and demonstrating $<4 \%$ energy resolution at $662 \mathrm{keV}$. Its energy resolution and light yield proportionality surpass $\mathrm{NaI}(\mathrm{Tl})$ and approach $\mathrm{LaBr}_{3}(\mathrm{Ce})$. These initial results are very promising considering that the crystal uniformity, light collection, and readout can still be optimized. We are exploring improvements in crystal growth technique and higher $\mathrm{Eu}^{2+}$ doping in order to evaluate the ultimate performance of $\mathrm{SrI}_{2}(\mathrm{Eu})$ and $\mathrm{BaI}_{2}(\mathrm{Eu})$ for high energy resolution gamma ray spectroscopy.

This work was supported by the Domestic Nuclear Detection Office in the Department of Homeland Security and by the NNSA, Office of Nonproliferation Research and Development (NA-22) of the U.S. Department of Energy under Contract No. DE-AC03-76SF00098, and was performed under the auspices of the U.S. DOE by Lawrence Livermore National Laboratory under Contract No. DE-AC5207NA27344. Oak Ridge National Laboratory is managed for the U.S, DOE by UT-Battelle under Contract No. DE-AC0500OR22725.

'E. V. D. van Loef, P. Dorenbos, C. W. E. van Eijk, K. Kramer, and H. H. Güdel, Appl. Phys. Lett. 79, 1573 (2001).

${ }^{2}$ K. S. Shah, J. Glodo, M. Klugerman, W. M. Higgins, T. Gupta, and P. Wong, IEEE Trans. Nucl. Sci. 51, 2395 (2004)

${ }^{3}$ C. Fiorini, A. Gola, M. Zanchi, A. Longoni, P. Lechner, H. Soltau, and L. Struider, IEEE Trans. Nucl. Sci. 53, 2392 (2006).

${ }^{4}$ R. Hofstadter, E. W. O'Dell, and S. T. Schmidt, IEEE Trans. Nucl. Sci. NS-11, 12 (1964).

${ }^{5}$ R. Hofstadter, U.S. Patent No. 3,373,279 (2 March 1968)

${ }^{6} \mathrm{~W}$. Lehmann, J. Electrochem. Soc. 122, 748 (1975).

${ }^{7}$ S. Kubota, J. Ruan (Gen), M. Itoh, S. Hashimoto, and S. Sakuragi, Nucl. Instrum. Methods Phys. Res. A 289, 253 (1990).

${ }^{8}$ P. A. Rodnyi, Radiat. Meas. 33605 (2001)

${ }^{9} \mathrm{~J}$. Selling, M. D. Birowosuto, P. Dorenbos, and S. Schweizer, J. Appl. Phys. 101, 034901 (2007).

${ }^{10} \mathrm{~V}$. Barnighausen and N. Schultz, Acta Crystallogr., Sect. B: Struct. Crystallogr. Cryst. Chem. B25, 1104 (1969).

${ }^{11}$ W.-S. Choong, K. M. Vetter, W. W. Moses, S. A. Payne, N. J. Cherepy, J.

D. Valentine, and G. Hull, IEEE Trans. Nucl. Sci. (unpublished).

${ }^{12}$ W.-S. Choong, G. Hull, W. W. Moses, S. A. Payne, N. J. Cherepy, J. D. Valentine, and B. W. Reutter, IEEE Trans. Nucl. Sci. (unpublished).

${ }^{13}$ G. Hull, W.-S. Choong, G. Bizarri, W. W. Moses, J. D. Valentine, S. Payne, N. Cherepy, and B. W. Reutter, IEEE Trans. Nucl. Sci. (unpublished). 